\title{
Intracellular Cleavage of Hepatitis C Virus RNA and Inhibition of Viral Protein Translation by Hammerhead Ribozymes
}

\author{
Naoya Sakamoto, Catherine H. Wu, and George Y. Wu \\ Department of Medicine, Division of Gastroenterology-Hepatology, University of Connecticut School of Medicine, Farmington, \\ Connecticut 06030
}

\begin{abstract}
To determine the effects of hammerhead ribozymes against hepatitis $\mathrm{C}$ virus (HCV) RNA on viral protein translation, a luciferase reporter gene vector, $\mathrm{pCMV} / \mathrm{T} 7-\mathrm{NCRC} \Delta$-luc, was constructed containing the $5^{\prime}$-noncoding region $\left(5^{\prime}\right.$-NCR) and part of the core region of HCV. Four ribozymes, Rz1Rz4, were designed to cleave at nucleotide positions 136160, 313-337, 496-520, and 373-388, respectively. Each ribozyme cleaved the target RNA at expected positions under cell-free conditions. Rz2 and Rz4 significantly suppressed translation of NCRC $\Delta$-luc RNA by 71 and $49 \%$, respectively. Translation of control luciferase mRNA lacking viral elements was not affected by the ribozymes. Furthermore, when NCRC $\Delta$-luc RNA and ribozymes were cotransfected into cells, $\mathrm{Rz} 2$ and $\mathrm{Rz} 4$ significantly suppressed expression by 73 and $56 \%$, respectively. In contrast, cleavage-deficient ribozymes with a point mutation in the hammerhead domain had no significant effect. To determine the effects of endogenously produced ribozymes, eukaryotic expression vectors for $\mathrm{Rz} 2$ and Rz4 were constructed. Cotransfection of the vectors with CMV/T7-NCRC $\Delta$-luc showed suppression of luciferase activities to 50 and $61 \%$, respectively. Moreover, transfection of pCMV/T7-NCRC $\Delta$-luc into stable Rz2 and Rz4 producer cells also showed substantial inhibition of luciferase activity. Ribozymes directed against the HCV genome can substantially and specifically inhibit viral gene expression under intracellular conditions. (J. Clin. Invest. 1996. 98:2720-2728.) Key words: gene therapy - luciferase reporter gene $\bullet$ catalytic RNA
\end{abstract}

\section{Introduction}

Ribozymes are RNA molecules that catalyze cleavage of a target RNA molecule based on sequence-specific recognition $(1,2)$. Hammerhead ribozymes are the smallest and the best characterized (3). They contain three RNA helices: I and III which hybridize to complementary strands of substrate RNA, and helix II, which cleaves the target RNA strand at a specific site. After cleavage and dissociation of the cleaved RNA mole-

Address correspondence to George Y. Wu, Department of Medicine, Division of Gastroenterology-Hepatology, University of Connecticut Health Center, Farmington, CT 06030. Phone: 860-679-3158; FAX: 860-679-3159; E-mail:wu@nso.uchc.edu

Received for publication 27 July 1996 and accepted in revised form 8 October 1996.

J. Clin. Invest.

(c) The American Society for Clinical Investigation, Inc. 0021-9738/96/12/2720/09 \$2.00

Volume 98, Number 12, December 1996, 2720-2728 cules, ribozymes can theoretically be recycled to catalyze additional reactions. Ribozymes are of much interest due to their potential for therapeutic applications (4). In the current study, we raised the possibility that an appropriately designed ribozyme could be used to specifically inhibit gene expression of hepatitis $\mathrm{C}$ virus (HCV), ${ }^{1}$ a major causative agent of acute and chronic hepatitis leading to end-stage liver failure and liver malignancy (5-7), and for which there is no satisfactory treatment.

Studies on the HCV genome have revealed that it is a plusstranded RNA of $\sim 10 \mathrm{~kb}$, and its structure has significant homology with the flavivirus and pestivirus $(8,9)$ families. The HCV genome consists of a single long open reading frame encoding a preprotein of $\sim 3,000$ amino acids for structural and nonstructural viral proteins. There are noncoding regions at $5^{\prime}$ - and $3^{\prime}$-termini, and the $3^{\prime}$-noncoding region is followed by poly-A or poly-U repeats. There is considerable variability of the nucleotide sequences between different strains of HCV. However, this variability is not evenly distributed throughout the genome. The $5^{\prime}$-end of the HCV genome including the $5^{\prime}$ noncoding region $\left(5^{\prime}-\mathrm{NCR}\right)$ and upstream half of the core region is the most conserved (10). Previous studies have shown that the $5^{\prime}$-NCR forms multiple stem loop structures, and that it has an internal ribosome entry site that mediates cap-independent translation of viral RNA $(11,12)$. Thus, the $5^{\prime}$-NCR is a critical structure required for viral protein synthesis and replication. Another important region is the core gene that encodes the viral capsid protein. The objective of the present study was to determine whether hammerhead ribozymes designed to cleave the HCV genome in the 5'-NCR, and the core regions of HCV-RNA could specifically and efficiently inhibit $\mathrm{HCV}$ viral gene expression.

\section{Methods}

Construction of $H C V$-luciferase reporter gene expression vectors. Fusion genes of the HCV-RNA and a luciferase reporter system were used to assess virus-specific protein synthesis. RNA was extracted by an acid guanidinium thiocyanate-phenol-chloroform method (13) from the plasma of a patient with chronic hepatitis $C$ (type Ia). The extracted RNA was reverse transcribed, and $585 \mathrm{bp}$ of the HCV-cDNA were amplified by PCR using a pair of primers encompassing the $5^{\prime}$-NCR and upstream part of the core region. The primers used were: NCR-Ia-S 5'-TTGCGGCCGCCAGCCCCCTGATGGGGGCGACACTCCACCAT -3';CORE-AS 5' - CCGGAT CCGGTACCCGGGCTGAGCCCAGG -3'.

The amplified DNA fragments were digested with NotI and BamHI, and cloned into NotI and ApaI sites of the pRcCMV (Clontech Labo-

1. Abbreviations used in this paper: $\mathrm{HBs}$, hepatitis B virus surface antigen; $\mathrm{HCV}$, hepatitis $\mathrm{C}$ virus; 5'-NCR, 5'-noncoding region; ODN, oligodeoxynucleotide. 


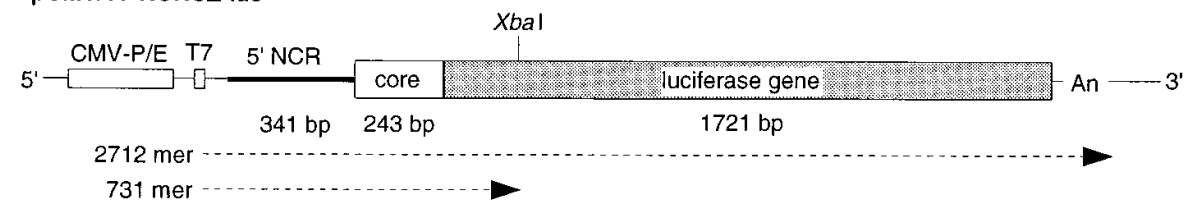

II. pCMV/T7-NCR-luc

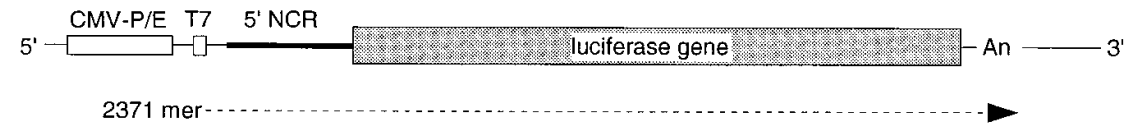

III. pCMv/T7-Iuc

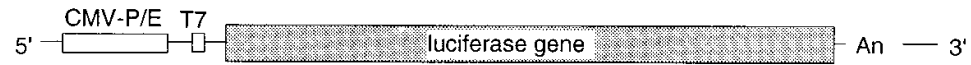

2141 mer

B

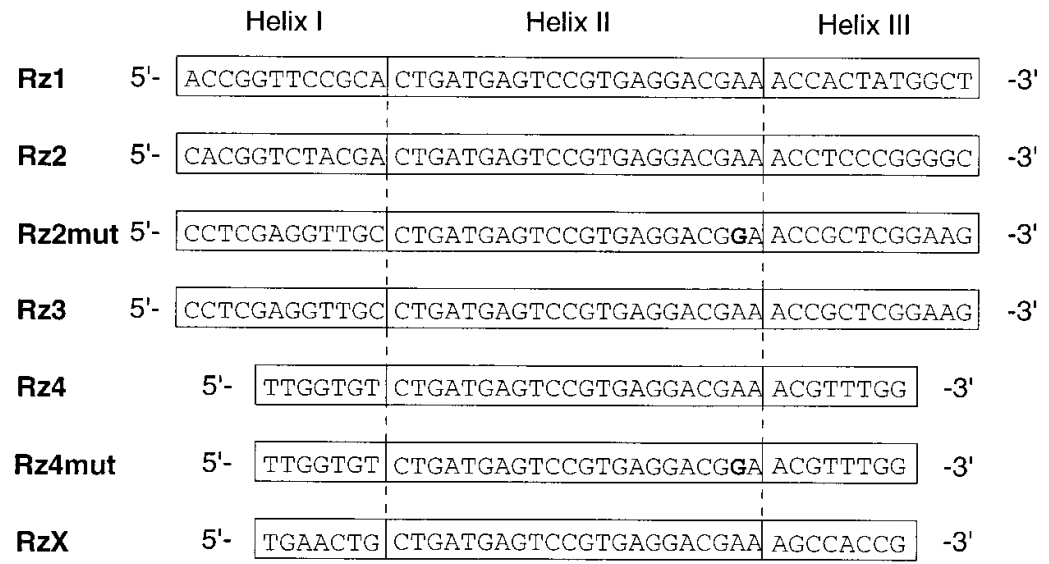

C

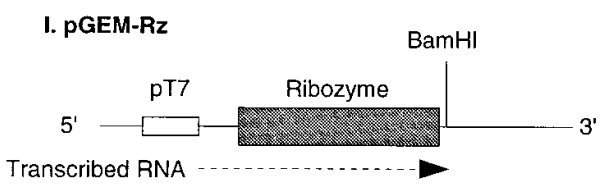

II. pCMV-Rz

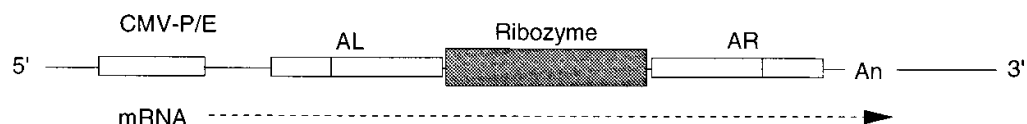

Figure 1. Structures and nucleotide sequences of luciferase fusion gene vectors and ribozymes. (A) Structures of the luciferase fusion gene vectors: $\mathrm{pCMV} / \mathrm{T} 7$ NCRC $\Delta$-luc, pCMV/T7-NCRluc, and pCMV/T7-luc; $C M V$ $P / E$, cytomegalovirus early promoter/enhancer; $p T 7, \mathrm{~T} 7$ promoter; $C \Delta$, part of the core region; $A n$, polyadenylated sequence; dashed arrow indicates the length of synthesized mRNA by T7 RNA polymerase. (B) Nucleotide sequences of the ribozymes used for the present study. Sequences for the helices I, II, and III are boxed. Rz1 and Rz2 are directed against the 5 '-noncoding region, and Rz3 and Rz4 are directed against the core region of hepatitis $\mathrm{C}$ virus genome. $\mathrm{RzX}$ is a ribozyme directed against the pre-S region of (an unrelated) hepatitis B virus genome. $(C)$ Structures of ribozyme RNA expression vectors. AL, 5' -part of the arm sequence for ribozyme. AR, 3'part of the arm sequence. ratories, Inc., Palo Alto, CA) with a BamHI- and ApaI-digested fragment of the pGEM-Luc (Promega Corp., Madison, WI) containing a full length luciferase gene (construct: pCMV/T7-NCRC $\Delta$-luc). Similarly, a NotI- and ApaI-digested fragment of pGEM-Luc was cloned between NotI and ApaI sites of pRcCMV (construct: pRcCMV/T7luc). In both constructs, expression of fusion genes was driven by a cytomegalovirus early promoter/enhancer, and also by the T7 promoter. Structures of the constructs are shown in Fig. $1 A$.

Construction of $\mathrm{HCV}$-directed hammerhead ribozymes. Four sets of ribozyme constructs were prepared using sequences shown in Fig. $1 \mathrm{~B} . \mathrm{Rz} 1$ and Rz2 were directed against the 5'-NCR (nucleotide [nt] 136-160 and 313-337 of the HCV genome, respectively), and Rz3 and
Rz4 were directed against the core region (nt 496-520 and 373-388, respectively. The nucleotide sequences of the target sites were derived from the reported sequences of the HCV genome $(8,9)$. To exclude antisense effects of the ribozymes, cleavage deficient ribozymes that have $\mathrm{A} \rightarrow \mathrm{G}$ point mutations in the catalytic loop of the hammerhead domain were prepared. These ribozymes allow binding to the target RNA, but lack cleavage ability $(14,15)$. The ribozyme template sequences were synthesized as pairs of partially overlapping oligonucleotides using a DNA synthesizer (380B; Applied Biosystems, Inc., Foster City, CA). After annealing both strands, the single-stranded gaps were filled in by Taq DNA polymerase (Life Technologies, Gaithersburg, MD). The synthesized DNA fragments were cloned 
into an EcoRV site of the pGEM5zf(+) (Promega Corp.) to make template plasmids for in vitro transcription (constructs: pGEM-Rz1, -Rz2, -Rz3, and -Rz4). To generate eukaryote expression vectors, the ribozyme sequences were subcloned into a multiple cloning site of the pRcCMV (constructs: pCMV-Rz2 and -Rz4), Fig. 1 C. Because intermolecular base pairing may alter ribozyme structure, ribozyme genes were positioned within a stem loop to stabilize the secondary structure (16). $5^{\prime}$ - and $3^{\prime}$ - arm sequences ( $A L$ and $A R$ in Fig. $1 C$, respectively) were as follows: AL 5' - CCAGTGTGCTGGACACACACACATCGAT -3' AR 5'- GTTAACACACACACACCCATCACACTGG - $3^{\prime}$.

As an additional negative control for the ribozyme reactions, a ribozyme vector was constructed from ribozymes unrelated to the HCV genome (construct: pCMV-RzX), which was directed against the pre-S region of hepatitis B virus genome. Nucleotide sequences of the constructs were confirmed by dideoxy-chain termination method.

Cell-free transcription of $H C V$ and ribozyme RNA. To determine the efficacy of ribozymes, an HCV viral RNA target was generated. RNA strands were synthesized by in vitro transcription using T7 RNA polymerase from linearized DNA templates, Fig. $1 A$. The NCRC $\Delta$-luc RNA (2,712-mer) and 5'-luc RNA (2,371-mer) were synthesized from pCMV/T7-NCRC $\Delta$-luc and pRcCMV/T7-luc, respectively. To prepare radiolabeled target RNA for cell-free cleavage assays of the ribozymes, NCRC $\Delta$-luc $\Delta$ RNA (731-mer) was synthesized from XbaI-digested pCMV/T7-NCRC $\Delta$-luc in the presence of $\left[\alpha{ }^{32} \mathrm{P}\right]$ UTP. Four different ribozymes were prepared in a similar fashion from BamHI-digested pGEM-Rz1, pGEM-Rz2, pGEM-Rz3, and pGEM-Rz4.

Analysis of ribozyme-mediated cleavage of viral RNA in cell-free conditions. 1 pmol of $\left[\alpha-{ }^{32} \mathrm{P}\right] \mathrm{UTP}-\mathrm{NCRC} \Delta-\operatorname{luc} \Delta$ RNA and varying molar ratios of ribozyme were mixed on ice, and incubated in the presence of $10 \mathrm{mM}$ Tris- $\mathrm{HCl}, \mathrm{pH} 7.4$ and $10 \mathrm{mM} \mathrm{MgCl}_{2}$ at $37^{\circ} \mathrm{C}$ for $1 \mathrm{~h}$. The mixtures were run on $5 \%$ polyacrylamide $/ 5 \mathrm{M}$ urea gels. After electrophoresis, the gels were subjected to autoradiography. All assays were performed in triplicate, and the amount of each DNA fragment was quantified by a PhosphorImager ${ }^{\mathrm{TM}}$. Cleavage ratios were expressed as a percentage of starting RNA.

In vitro translation. The NCRC $\Delta$-luc RNA and ribozyme RNA were mixed with rabbit reticulocyte lysate (Promega Corp.), and incubated at $30^{\circ} \mathrm{C}$ for $1 \mathrm{~h}$ with or without $\left[{ }^{35} \mathrm{~S}\right]$ methionine. The synthesized proteins were analyzed by SDS-PAGE and autoradiography and incorporation of $\left[{ }^{35} \mathrm{~S}\right]$ methionine was quantified by the PhosphorImager $^{\mathrm{TM}}$. Efficiency of the $5^{\prime}$-NCR-dependent translation was quantified by measurement of luciferase activity.

Cells and cell culture. As a model for HCV RNA gene expression in human hepatocytes, a human hepatoma cell line, Huh7, was

A
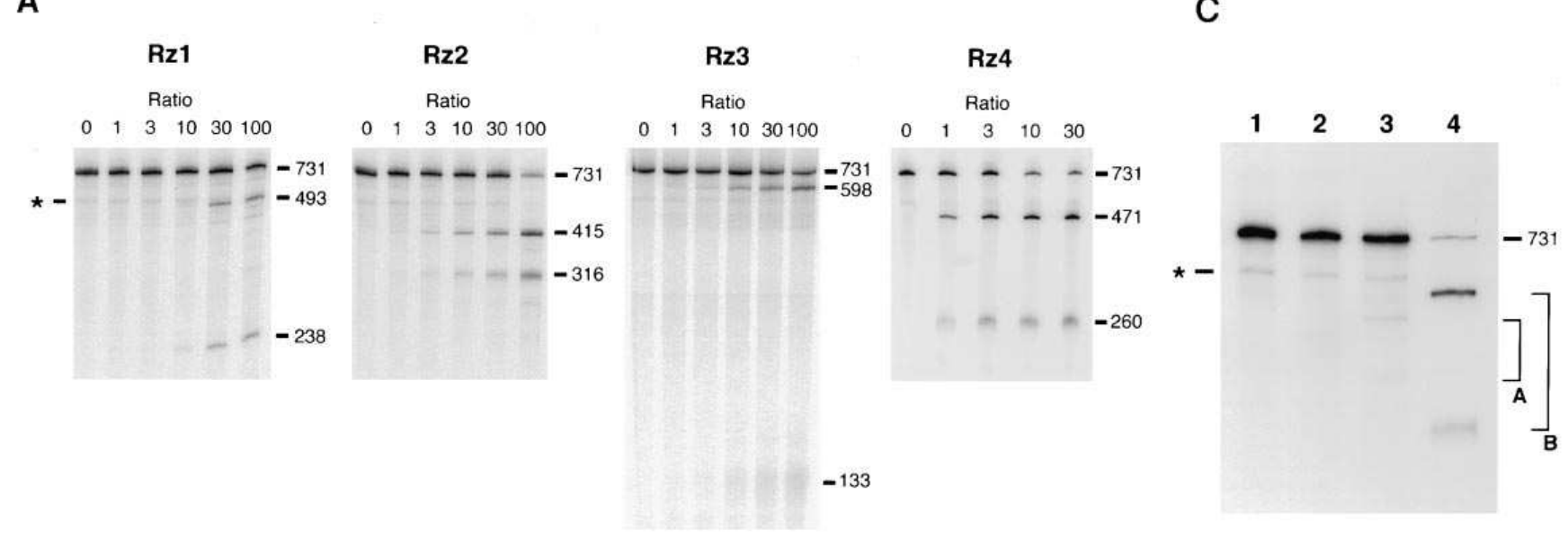

C

B

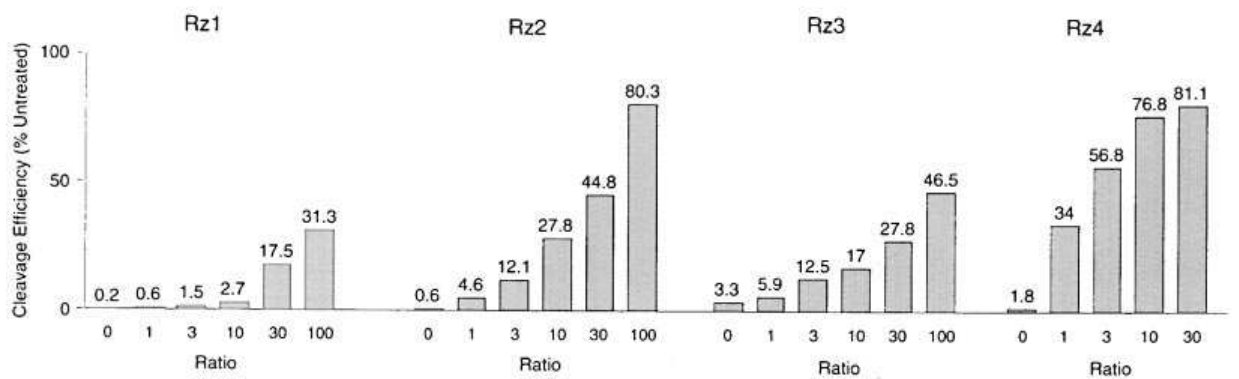

Figure 2. Cell-free cleavage analyses of the ribozymes and target RNA. $(A)$ Cleavage of RNA target by ribozymes. The ribozymes and 1 pmol of

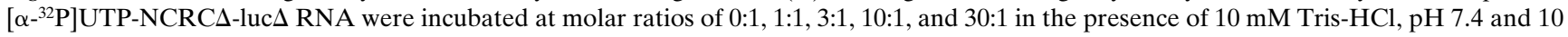
$\mathrm{mM} \mathrm{MgCl}{ }_{2}$ at $37^{\circ} \mathrm{C}$ for $1 \mathrm{~h}$. After incubation, reaction mixtures were run on $5 \%$ polyacrylamide $/ 5 \mathrm{M}$ urea gel, and subjected to autoradiography. Numbers beside the bands indicate expected nucleotide lengths of labeled RNA. The top band (731 mer) in each lane shows uncleaved target; the other two bands in the same lane show the cleaved targets. $(B)$ Quantification of cleavage extent of ribozymes. The amount of each RNA band was quantified by PhosphorImager ${ }^{\mathrm{TM}}$, and the cleavage efficiency was expressed as percent of the starting RNA. $(C)$ Cell-free cleavage of target RNA and catalytic loop mutant ribozymes. ${ }^{32} \mathrm{P}$-labeled NCRC $\Delta$-luc $\Delta$-RNA was incubated at $37^{\circ} \mathrm{C}$ for $1 \mathrm{~h}$ with 100 times (lanes 1 and 2 ) or 10 times (lanes 3 and 4) molar excess of Rz2mut, Rz4mut, Rz2, and Rz4 (lanes 1-4, respectively). *Incomplete length RNA occurred by partial transcription termination of T7 RNA polymerase by a 10 adenine repeat at nucleotide position 364-373 of the HCV genome. $A$ and $B$, cleavage products by Rz2 and Rz4, respectively. 
maintained in DME (Life Technologies) supplemented with $10 \%$ fetal bovine serum at $37^{\circ} \mathrm{C}$ under $5.5 \% \mathrm{CO}_{2}$.

RNA transfection. To assess the intracellular activity of ribozymes, RNA transfection was performed using a modification of the method of Wang et al. (12). Huh7 cells were plated onto 48-well plastic plates at $80 \%$ confluence. The NCRC $\Delta$-luc RNA and ribozyme RNA were mixed in varying molar ratios. Total RNA, $2 \mu \mathrm{g}$, was mixed with $6 \mu \mathrm{g}$ of lipofectamine (Life Technologies) in phosphate-buffered saline. To minimize extracellular cleavage, cells were exposed to the RNA-lipofectamine complexes for only $2 \mathrm{~h}$, and replaced by complete culture medium. Luciferase activities were measured after $6 \mathrm{~h}$ of transfection.

DNA transfection. To determine the efficiencies of the ribozyme expressed within cells by transfected plasmid vectors, DNA cotransfection was performed. The pCMV/T7-NCRC $\Delta$-luc or the pCMV/T7luc, and the pCMV-Rz2 or the pCMV-Rz4 were mixed in varying molar ratios. Total DNA of $1.6 \mu \mathrm{g}$ was mixed with $8 \mu \mathrm{g}$ of lipofectamine, and added to Huh7 cells plated onto 24-well plate. Luciferase activities were measured after $2 \mathrm{~d}$ of transfection.

Construction of Huh7 cells constitutively producing ribozyme $R N A$. DNA and RNA transfections result in transient synthesis of the protein of interest. There can be considerable variability in the levels of product. To produce a test system with a stable production of ribozyme, cell lines were prepared that constitutively produce ribozymes. Huh7 cells were transfected by a calcium phosphate method, with plasmids pCMV-Rz2 or pCMV-Rz4, which contain a neomycin resistance gene (17). Stable transfectants were cloned by selection with G418 (Life Technologies). Production of ribozyme RNA was measured by ribonuclease protection assay (RPA II ${ }^{\mathrm{TM}} \mathrm{Ri}-$ bonuclease Protection Assay Kit; Ambion Inc., Austin, TX), and clones producing the highest levels of the ribozymes were used for further assays (cell clones: Huh7/Rz2 and Huh7/Rz4).

Transfection to Huh7/Rz transfectants. To determine the effect of constitutive ribozyme production on $\mathrm{HCV}$-directed protein synthesis, luciferase reporter gene vectors described above were transfected into Huh7/Rz2 and Huh7/Rz4 cell lines. Luciferase assays were performed after $5 \mathrm{~d}$ of transfection. To normalize the efficiencies of the DNA transfections, cells were cotransfected with pSV-HBVsurf, a plasmid containing the hepatitis B virus surface (HBs) antigen gene. The HBs antigen was quantified by an Abbott ELISA (Abbott Laboratories, North Chicago, IL) method as described by the manufacturer.

Luciferase assays. Luciferase activity was quantified by a luminometer using a Luciferase Assay Kit (Promega Corp.). Total cell protein was determined by Bio-Rad (Richmond, CA) assay as described by the manufacturer. Assays were performed in triplicate and the results expressed as means $\pm 2 \mathrm{SD}$ in relative light units normalized to cell protein or as percent activities of untreated samples.

Statistical analyses. Statistical analyses were performed using Student's $t$ test with $P$ values of $<0.05$ considered to be statistically significant.

\section{Results}

Incubation of the ribozymes and target RNA at several molar ratios under cell-free conditions produced RNA bands of the sizes anticipated for each ribozyme (Fig. $2 A$ ). As expected, the extent of cleavage of target RNA increased with increasing ratios of ribozyme to target. Fig. $2 B$ shows that at a $30: 1$ ribozyme to target ratio, Rz1, Rz2, Rz3, and Rz4 had cleavage extents of $17.5,44.8,27.8$, and $81.1 \%$, respectively. The target RNA was not cleaved by catalytic domain mutant ribozymes, Rz2mut and Rz4mut, even at 100:1 ribozyme to target molar ratios (Fig. 2 C).

In vitro translation of 5'-luc and NCR-luc RNA yielded a protein of a size expected for luciferase $(61 \mathrm{kD})$. The trans-

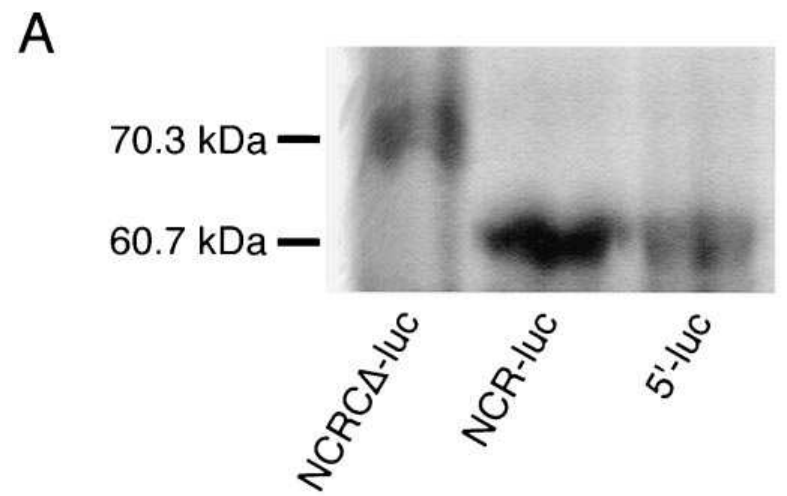

B

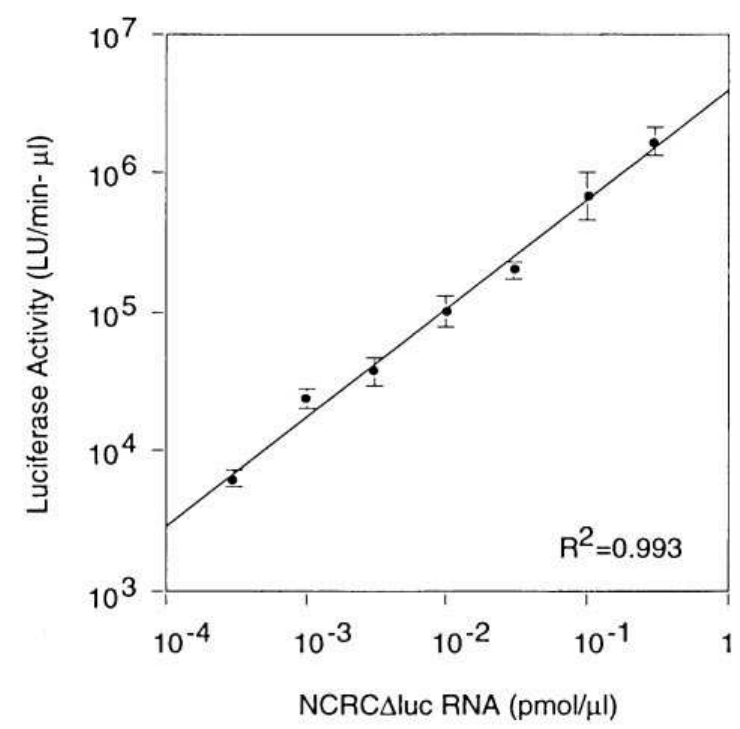

Figure 3. In vitro translation of a synthetic luciferase reporter RNA transcript. (A) RNA was synthesized from pCMV/T7-NCRC $\Delta$-luc, pCMV/T7-NCR-luc, and pCMV/T7-luc by T7 RNA polymerase to form NCRC $\Delta$-luc, NCR-luc, and 5'-luc, respectively. Each RNA was incubated in rabbit reticulocyte lysate with $\left[{ }^{35} \mathrm{~S}\right]$ methionine at $30^{\circ} \mathrm{C}$ for $1 \mathrm{~h}$. The reaction mixtures were analyzed by SDS-PAGE and subjected to autoradiography. Efficiency of the $5^{\prime}$-NCR-dependent translation was quantified by luciferase activities. (B) A log-log plot of luciferase activity versus amount of template NCRC $\Delta$-luc RNA. Error bars represent \pm SD.

lated product of the NCRC $\Delta$-luc RNA appeared to be $70 \mathrm{kD}$, which is consistent with the expected size of the HCV coreluciferase fusion protein (Fig. $3 A$ ). All the translated products were found to have luciferase activity (Table I). Furthermore, luciferase activities of the core-luciferase fusion protein adjusted for the molar amounts of translated proteins were equivalent to the native luciferase protein, suggesting that the synthesized fusion proteins fully retained their enzymatic activities. In addition, a log-log plot of luciferase activity as a function of concentration of template NCRC $\Delta$-luc RNA produced a linear relationship with a strong correlation efficient, 0.993 (Fig. 3 B).

To determine whether the specific cleavage of the HCVRNA by ribozyme could affect 5 -NCR-dependent translation, in vitro translation was performed with full length 
Table I. Luciferase Activities of In Vitro-translated Luciferase and Hepatitis C Virus Core Luciferase Fusion Proteins

\begin{tabular}{lcc}
\hline Template RNA & Luciferase activities & $\begin{array}{c}\text { Adjusted luciferase } \\
\text { activity* }\end{array}$ \\
\hline & $R L U / \mu l^{\ddagger}$ & $\begin{array}{c}\text { Percentage of native protein } \\
\text { s }\end{array}$ \\
$5^{\prime}$-luc & $8.3 \times 10^{6}$ & 100 \\
NCR-luc & $2.1 \times 10^{7}$ & 99 \\
NCRC $\Delta$-luc** & $1.4 \times 10^{7}$ & 109 \\
\hline
\end{tabular}

"5'-luc, synthetic luciferase mRNA; " NCR-luc, synthetic RNA of the 5'noncoding region of hepatitis $\mathrm{C}$ virus genome and luciferase gene; **NCRC $\Delta$-luc, synthetic RNA of the fusion gene of the $5^{\prime}$-noncoding region and upstream part of the core region of the hepatitis $\mathrm{C}$ virus genome followed by luciferase gene; ${ }^{*} \mathrm{RLU}$, relative light units; *Adjusted luciferase activity, luciferase activity adjusted by molar amounts of the translated proteins. ${ }^{\S}$ Values are shown as percent activities of the native luciferase protein.

NCRC $\Delta$-luc RNA as template in the presence of the ribozymes. Fig. 4 shows that with a 30 -fold excess, Rz2 and Rz4 decreased luciferase activities by 69.4 and $50.9 \%$, respectively. In contrast, there were no significant effects of Rz1 and Rz3 on luciferase activity. To determine whether this observed effect was due to nonspecific inhibition of translation by the ri- bozymes, 5'-luc RNA that lacks HCV viral elements was used as a control transcript in the presence of ribozymes Rz2 and Rz4. Luciferase activity generated by this transcript was not significantly affected by either ribozyme under identical conditions (Fig. 4). Moreover, Rz2mut and Rz4mut had no inhibitory effects on luciferase activities.

To determine whether the ribozymes were active when introduced inside cells, NCRC $\Delta$-luc RNA and ribozymes were cotransfected in varying molar ratios as described above. The ribozymes Rz2 and Rz4 significantly suppressed expression of HCV-RNA by 73.0 and $55.5 \%$, respectively, while Rz2mut and Rz4mut had no significant effect (Fig. 5). As had been observed in the cell-free experiments, Rz1 and Rz3 were considerably less active under identical conditions.

Based on the results of the above cell-free assays, and the RNA transfections, the two most effective ribozymes, Rz2 and the Rz4, were used to construct eukaryote expression vectors, pCMV-Rz2 and pCMV-Rz4. Cotransfection of pCMV/T7NCRC $\Delta$-luc with a 20-fold molar excess of pCMV-Rz2 and pCMV-Rz4 showed suppression of luciferase activities to $50.2 \pm 7.6 \%$ and $61.2 \pm 3.7 \%$, respectively (Fig. $6 \mathrm{~A}$ ). As a control for nonspecific ribozyme-target interaction, $\mathrm{pCMV} / \mathrm{T} 7$ NCRC $\Delta$-luc was cotransfected with pCMV-RzX, a plasmid encoding a ribozyme directed against non-HCV sequences. In addition, ribozyme vectors were cotransfected with pCMV/T7luc lacking any $\mathrm{HCV}$ viral components. In both cases, there were
$\mathrm{NCRC} \Delta$-luc $+\mathrm{Rz1}$

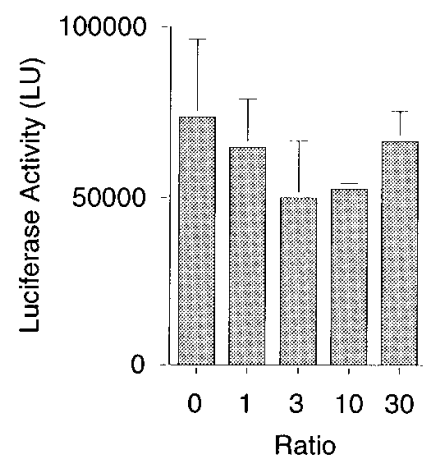

$5^{\prime}$ luc $+\mathrm{Rz2}$

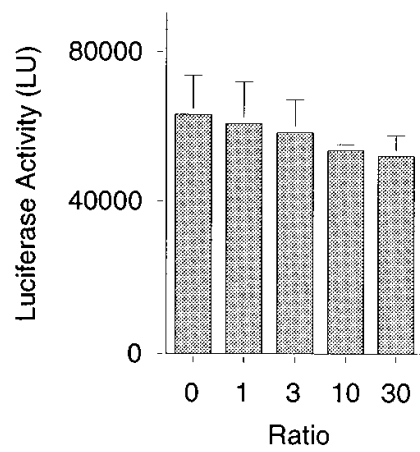

$\mathrm{NCRC} \Delta-\mathrm{luc}+\mathrm{Rz2}$

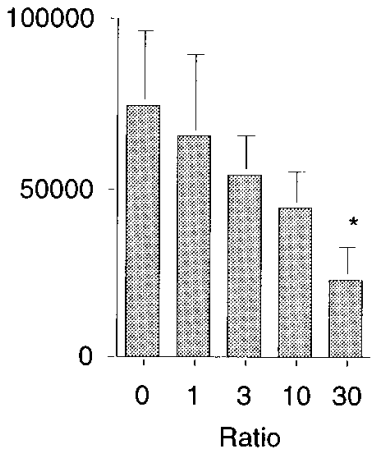

$5^{\prime l u c}+R z 4$

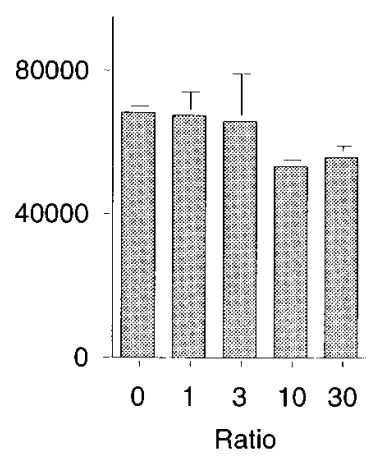

$\mathrm{NCRC} \Delta-$ luc $+\mathrm{Rz3}$

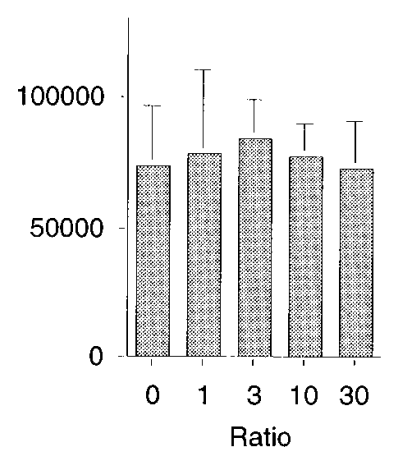

NCRC $\Delta$-luc + Rz2mut

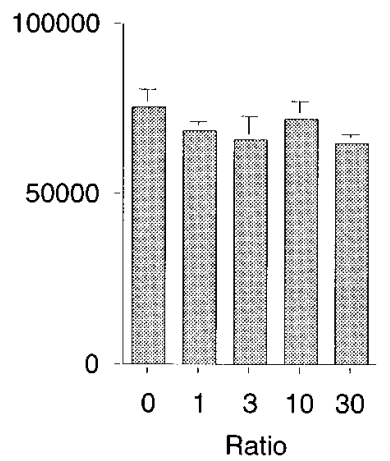

$\mathrm{NCRC} \Delta$-luc + Rz4

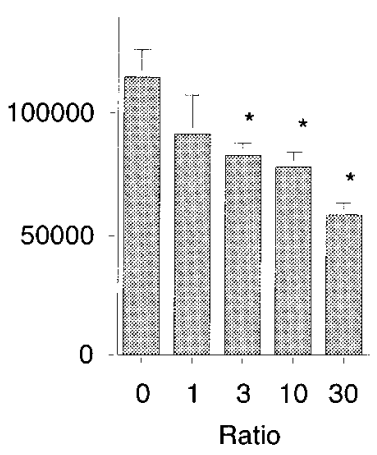

NCRC $\Delta-$ luc + Rz4mut

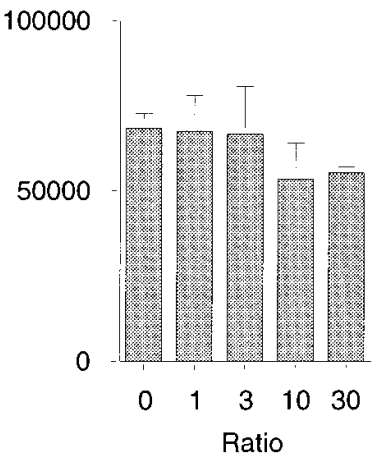

Figure 4. In vitro translation of NCRC $\Delta$-luc and 5'-luc RNA with ribozymes. NCRC $\Delta$-luc RNA or $5^{\prime}$-luc RNA were incubated in rabbit reticulocyte lysate in the presence of ribozymes as described in the Methods section. Luciferase activities were calculated as means \pm 2 SD, and were expressed as light units. $\left({ }^{*} P<0.05\right)$. Ratios denote ribozyme to target (mole/mole) ratios. 

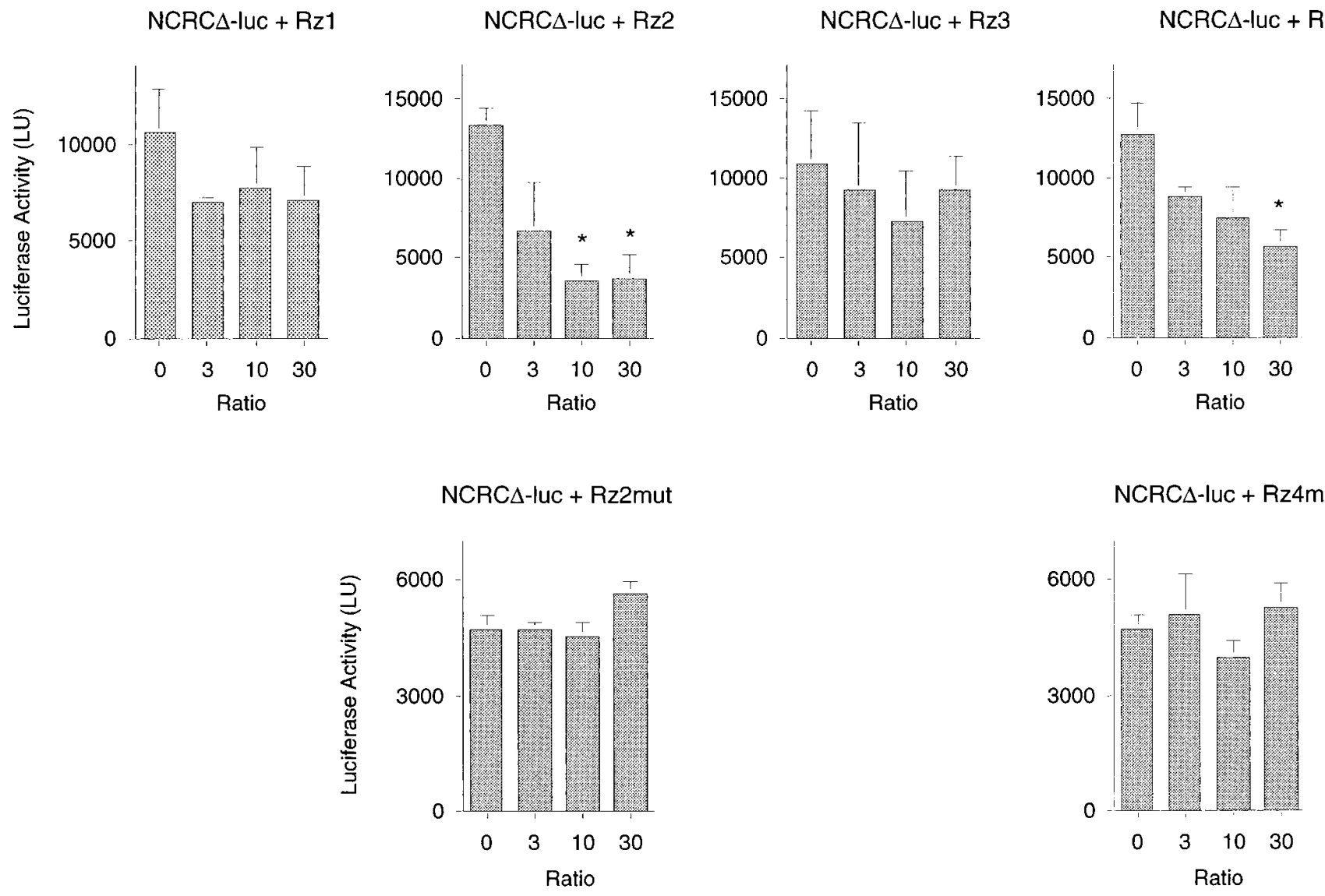

Figure 5. RNA transfection of NCRC $\Delta$-luc RNA and ribozymes. Huh7 cells plated onto 48 -well plastic plates at $80 \%$ confluence were transfected by lipofectamine with NCRC $\Delta$-luc RNA and varying ratios of ribozymes as described in the Methods section. Luciferase activity was quantified after $6 \mathrm{~h}$ of transfection and the results are shown as light units. Error bars indicate $\pm 2 \mathrm{SD}(* P<0.05)$. Ratios denote ribozyme to NCRC $\Delta$-luc RNA (mole/mole) ratios.

no significant effects on the luciferase activities, suggesting that the decreased luciferase activities were due to sequencespecific cleavages of HCV-RNA by directed ribozymes, and that the RNA was active both in the form of ribozyme from endogenously produced messenger RNA as well as exogenously introduced ribozyme.

To assess the effect of constitutively produced endogenous ribozyme, Huh7 cell lines stably transfected with pCMV-RZ2 or pCMV-RZ4 were studied. To establish ribozyme-producing cell lines, Huh7 cells were transfected with pCMV-Rz2 or pCMV-Rz4, and stably transfected clones were selected and isolated by G418 treatment as described above. The levels of ribozymes in the resulting clones, Huh7/Rz2 and Huh7/Rz4, were calculated to be $7 \times 10^{6}$ and $8 \times 10^{6}$ copies $/ \mu$ g cellular RNA, respectively. There were no differences in the cell morphology, growth rate, or protein content per cell between transfected and nontransfected Huh7 cells (data not shown). Huh7/Rz2, Huh7/Rz4, and nontransfected Huh7 cells were transiently transfected with pCMV/T7-NCRC $\Delta$-luc or control pCMV/T7-luc plasmids. Luciferase activities were significantly inhibited in Huh7/Rz4 cells transfected with pCMV/T7NCRC $\Delta$-luc to $50.0 \pm 6.4 \%$ of that of ribozyme-negative Huh7 cells (Fig. $6 \mathrm{~B}$ ). Transfection of the same plasmid vector into Huh7/Rz2 cells showed decreased luciferase activities to $70.0 \pm 8.0 \%$. Transfection of the control pCMV/T7-luc into the
Huh7/Rz2 and Huh7/Rz4 resulted in no significant differences in luciferase activity compared with that of the Huh7 cells under identical conditions.

\section{Discussion}

The results indicate that although all four ribozymes were capable of cleaving target viral RNA in cell-free conditions, only two ribozymes, Rz2 and Rz4, significantly inhibited marker gene expression when introduced into cells. These ribozymes were not directed against the same region of the viral genome. Rz2 was synthesized to cleave just upstream of the start codon of the viral transcript, while Rz4 was designed to interfere with the core region. The discrepancy between cell-free and intracellular effects has been described previously, and may be due to several factors. For example, double-stranded regions of folded single-stranded RNA, interaction sites for RNA-binding proteins, and regions that have homology with other endogenous RNA sequences have been shown to be much less accessible to ribozymes (4). Before performing the current experiments, an mFOLD structural prediction program was used to estimate folding of single-stranded RNA, and likely sites for successful ribozyme attack (18). The mFOLD prediction of secondary structure of the HCV genome is shown in Fig. 7 which indicates that the target sites for $\mathrm{Rz} 2$ and $\mathrm{Rz} 4$ are pre- 

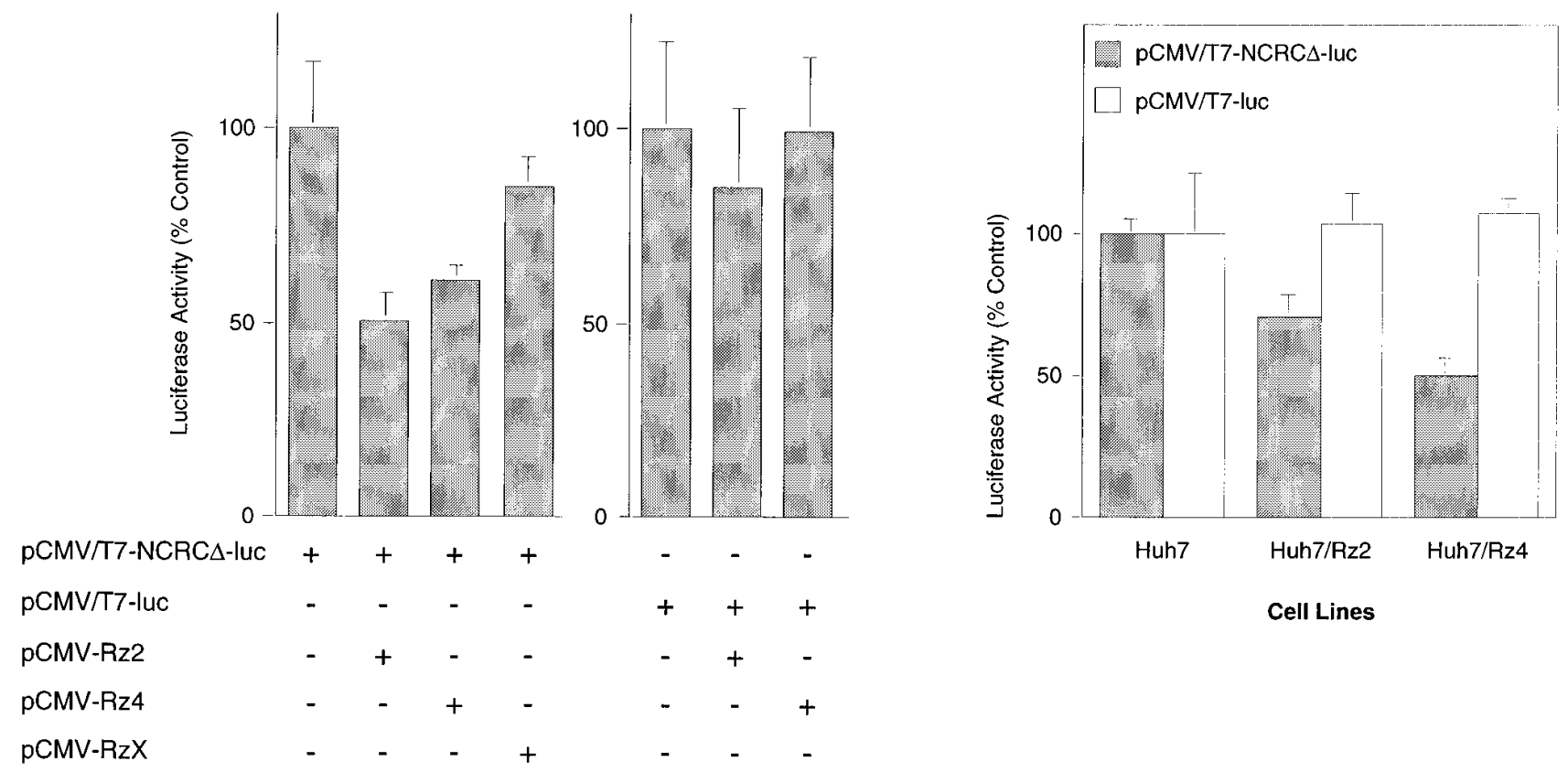

Figure 6. Effects of the ribozyme expression vectors on translation of the hepatitis C virus RNA. (A) DNA cotransfection of pCMV/T7NCRC $\Delta$-luc or pCMV/T7-luc and 20-fold molar excess of ribozyme expression vectors, pCMV-Rz2, pCMV-Rz4, and pCMV-RzX. Efficiencies of transfection were normalized to levels of HBs antigen synthesized from a cotransfected plasmid, pSV-HBVsurf. Luciferase activities were expressed as a percentage of ribozyme-negative controls. Error bars indicate \pm 2 SD. (B) Plasmids pCMV/T7-NCRC $\Delta$-luc and pCMV/T7-luc were transfected into Huh7 cells to produce constitutive production of ribozyme RNA in Huh7/Rz2 and Huh7/Rz4 cell lines as described in the Methods section. Values are expressed as a percentage of luciferase activity of Huh7 cells transfected with pCMV/T7-NCRC $\Delta$-luc or pCMV/T7-luc. Error bars indicate \pm 2 SD.

dicted to be in a single-stranded region, while those for Rz1 and Rz3 are predicted to be in a double-stranded region of the HCV-RNA. The observed differential cleavage activity among the four ribozymes is consistent with this prediction. Whether such folding actually occurred in the cells is not known. Nevertheless, the results confirm the fact that cleavage under cellfree conditions does not always reflect activities of reactions within cells. Recently, a systematic approach using a library to select optimal ribozyme sequences (16) has demonstrated that effective target sites for the ribozymes are limited to singlestranded gaps of mRNA, which is consistent with our results.

In studies described here, a luciferase gene was expressed as a fusion protein of the $\mathrm{HCV}$ core protein that is translated simultaneously by the $5^{\prime}$-NCR. Therefore, the measured internal luciferase activity directly reflects the synthesis of core protein. The fact that the ribozymes had no effect on the luciferase (T7-luc) template RNA lacking viral 5' -NCR suggested that the observed effects of the ribozymes were not due to recognition of nonviral sequences.

Antisense oligodeoxynucleotides (ODN) directed to the 5 '-NCR have been shown to inhibit the translation of the HCV-RNA and virus replication (19-21). In previous studies, antisense ODNs directed against a region adjacent to the start codon effectively inhibited viral expression while the ODNs directed against only the protein-coding region were not effective. However, effective sites for ODNs are different from those for our ribozymes, likely due to the different mecha- nisms of inhibition. As we have shown in the present study, mutant ribozymes containing substitution of key nucleotides in the catalytic domain of the helix II, allowing binding to the target, but lacking cleavage activity, demonstrated no inhibitory effects in cells, which was consistent with the previous studies $(14,15)$. Our data suggest that the mechanism for the inhibitory effects of the ribozymes in the cells is mainly due to sequence-specific cleavage.

Ribozymes have been previously used successfully to inhibit gene expression of other viruses, and also of neoplastic cells $(15,22)$. Experiments with ribozymes and hepatitis B virus $(23,24)$ have demonstrated sequence-specific cleavage of pregenomic mRNA by ribozymes. The present study demonstrates intracellular effects of the ribozymes against the HCV.

The 5'-NCR of HCV was selected as a potential target for cleavage because this region has been shown to mediate ribosome binding of the HCV-RNA followed by cap-independent translation initiation $(11,12)$. Nucleotide alterations, partial deletion, or total removal of the $5^{\prime}$-NCR abolishes its translation initiation function (25-27). Moreover, the HCV genome consists of a single open reading frame. Virus proteins are maturated through post- or cotranslational processing of viral preprotein by microsomal signal peptidase or by viral serine protease. Because the $5^{\prime}$-NCR is the only translation initiation site in the viral genome, cleavage of the region by the ribozymes could potentially block the expression of all the encoded viral proteins. Transfection of full length $\mathrm{HCV}-\mathrm{RNA}$ in cultured 


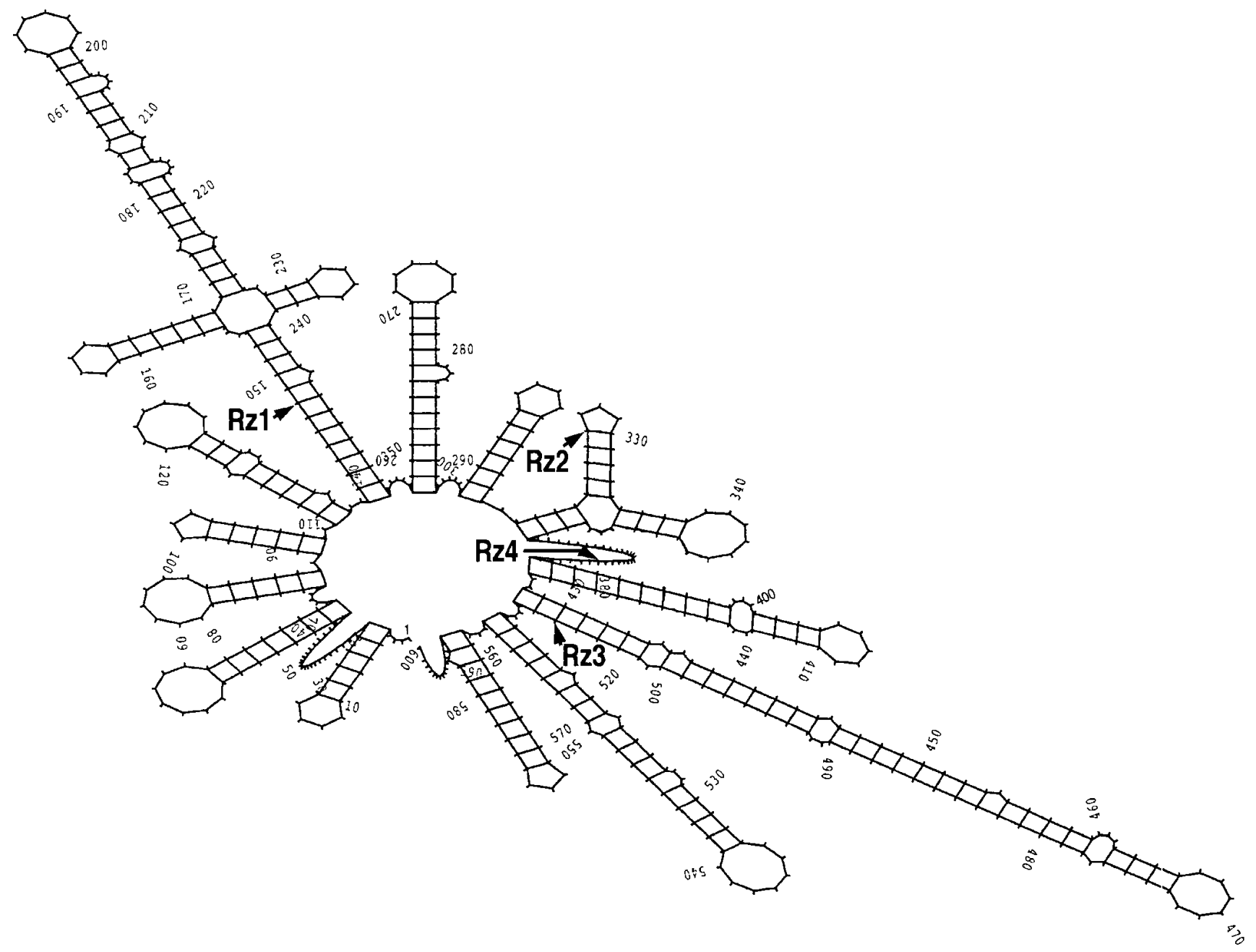

Figure 7. Predicted secondary structure of hepatitis C virus RNA. An upstream sequence of a reported hepatitis $\mathrm{C}$ virus genome (nucleotide position 1 to 1400$)$ was analyzed using an mFOLD program $(9,18)$. The folding plot of the RNA from nucleotide positions 1 to 600 is shown. Arrows indicate cleavage sites of the indicated ribozymes.

liver cells has shown that full length $5^{\prime}$-NCR is required for replication and virus propagation (28). Ribozymes might block replication of viral genome as well as viral protein expression resulting in more effective suppression of HCV infection.

The HCV genome is known to have considerable variability among its subtypes, and also among strains of the same subtype (9). Moreover, multiple closely related strains of the viruses may be present in a single patient (29). Because sequence mismatches between the ribozyme and target may considerably affect the efficiency of their cleavage reaction, it is important to use well-conserved regions as ribozyme targets. The $5^{\prime}$-NCR and upstream half of the core region are most highly conserved in the HCV genome (99.9\%) (10). The sequences selected as targets of the ribozymes in the current study are identical to the known HCV subtypes as well as strains of the same subtypes.

Studies on HCV have been hampered by the difficulty of establishing infection models. Humans and other primates are the only known hosts for HCV infection. Furthermore, only a limited number of cell lines can support HCV replication (30-33). Viral replication in these cells, however, is unstable, and the viral titers can be measured only by PCR. Thus, meth- ods to detect and quantify virus replication and the protein expression are limited. In the present study, we adopted the luciferase reporter gene system that is linked to the initiation of translation by $5^{\prime}$-NCR because it is a sensitive and quantitative method. However this chimeric construct, while convenient, may not reflect the actual intracellular folding of the complete $\mathrm{HCV}$ genome. Although the data do not necessarily predict that these ribozyme sequences will be effective against a natural HCV infection, the results do indicate that intracellular delivery of hammerhead ribozymes either by RNA itself or by expression from DNA expression vectors into the $\mathrm{HCV}$-infected hepatocytes can substantially inhibit HCV translational targets.

\section{Acknowledgments}

We thank Dr. Yoshinori Ito and Dr. Juan Ruiz for their excellent technical advice.

This work was supported in part by grants from the NIDDK: DK42182 (G.Y. Wu), the Immune Response Corporation (C.H. Wu), and the Herman Lopata Chair in Hepatitis Research (G.Y. Wu). Two of the authors (G.Y. Wu and C.H. Wu) hold equity in the Immune Response Corporation. 


\section{References}

1. Altman, S. 1989. Ribonuclease P: an enzyme with a catalytic RNA subunit. Adv. Enzymol. 62:1-36.

2. Cech, T.R. 1987. The chemistry of self-splicing RNA and RNA enzymes. Science (Wash. DC). 236:1532-1539.

3. Uhlenbeck, O.C. 1987. A small catalytic oligoribonucleotide. Nature (Lond.). 328:596-600.

4. James, W., and A. Shamkhani. 1995. RNA enzymes as tools for gene ablation. Curr. Opin. Biotechol. 6:44-49.

5. Sakamoto, N., C. Sato, H. Haritani, S. Maekawa, M. Kurosaki, N. Enomoto, Y. Hoshino, J. Tazawa, M. Nishimura, and F. Marumo. 1993. Detection of hepatitis $\mathrm{C}$ viral RNA in sporadic acute non-A, non-B hepatitis by polymerase chain reaction. Its usefulness for the early diagnosis of seronegative infection. J. Hepatol. 17:28-33.

6. Choo, O.L., G. Kuo, A.J. Weiner, L.R. Overby, D.W. Bradley, and M. Houghton. 1989. Isolation of a cDNA clone derived from a blood borne non-A, non-B viral hepatitis genome. Science (Wash. DC). 244:359-362.

7. Esteban, J.I., R. Esteban, L. Viladomiu, J.C. López-Talavera, A. González, J.M. Hernández, M. Roget, V. Vargas, J. Genesca, M. Buti, and J. Guardia. 1989. Hepatitis C virus antibodies among risk groups in Spain. Lancet. ii:294-297.

8. Kato, N., M. Hijikata, Y. Ootsuyama, M. Nakagawa, S. Ohkoshi, T. Sugimura, and K. Shimotohno. 1990. Molecular cloning of the human hepatitis C virus genome from Japanese patients with non-A, non-B hepatitis. Proc. Natl. Acad. Sci. USA. 87:9524-9528.

9. Choo, Q.L., K.H. Richman, J.H. Han, K. Berger, C. Lee, C. Dong, C. Gallegos, D. Coit, R. Medina-Selby, P.J. Barr et al. 1991. Genetic organization and diversity of the hepatitis C virus. Proc. Natl. Acad. Sci. USA. 88:2451-2455.

10. Okamoto, H., S. Okada, Y. Sugiyama, K. Kurai, H. Iizuka, A. Machida, Y. Miyakawa, and M. Mayumi. 1991. Nucleotide sequence of the genomic RNA of hepatitis $\mathrm{C}$ virus isolated from a human carrier: comparison with reported isolates for conserved and divergent regions. J. Gen. Virol. 72:2697-2704.

11. Tsukiyama-Kohara, K., N. Iizuka, M. Kohara, and A. Nomoto. 1992. Internal ribosome entry site within hepatitis C virus RNA. J. Virol. 66:1476-1483.

12. Wang, C., P. Sarnow, and A. Siddiqui. 1993. Translation of human hepatitis $\mathrm{C}$ virus RNA in cultured cells is mediated by an internal ribosome-binding mechanism. J. Virol. 67:3338-3344.

13. Chomczynski, P., and N. Sacchi. 1987. Single-step method of RNA isolation by acid guanidinium thiocyanate-phenol-chloroform extraction. Anal. Biochem. 162:156-159.

14. Kashani, S.M., T. Funato, V.A. Florenes, O. Fodstad, and K.J. Scanlon. 1994. Suppression of the neoplastic phenotype in vivo by an anti-ras ribozyme. Cancer Res. 54:900-902.

15. Zhou, C., I.C. Bahner, G.P. Larson, J.A. Zaia, J.J. Rossi, and E.B. Kohn. 1994. Inhibition of HIV-1 in human T-lymphocytes by retrovirally transduced anti-tat and rev hammerhead ribozymes. Gene. 149:33-39.

16. Lieber, A., and M. Strauss. 1995. Selection of efficient cleavage sites in target RNAs by using a ribozyme expression library. Mol. Cell. Biol. 15:540-551.

17. Graham, F.L., and A.J. Van der Eb. 1973. A new technique for the assay of infectivity of human adenovirus 5 DNA. Virology. 52:456-467.
18. Zuker, M. 1989. On finding all suboptimal foldings of an RNA molecule. Science (Wash. DC). 244:48-52.

19. Wakita, T., and J.R. Wands. 1994. Specific inhibition of hepatitis C virus expression by antisense oligodeoxynucleotides. In vitro model for selection of target sequence. J. Biol. Chem. 269:14205-14210.

20. Mizutani, T., N. Kato, M. Hirota, S. K., A. Murakami, and K. Shimotohno. 1995. Inhibition of hepatitis C virus replication by antisense oligonucleotide in cultured cells. Biochem. Biophys. Res. Commun. 212:906-911.

21. Wu, C.H., A. Siddiqui, and G.Y. Wu. 1995. Targeted inhibition of HCV promoter activity using HCV specific antisense DNA. Hepatology. 22:331a. (Abstr.)

22. Feng, M., G. Cabrera, J. Deshane, K.J. Scanlon, and D.T. Curiel. 1995. Neoplastic reversion accomplished by high efficiency adenoviral-mediated delivery of an anti-ras ribozyme. Cancer Res. 55:2024-2028.

23. von Weizsacker, F., H.E. Blum, and J.R. Wands. 1992. Cleavage of hepatitis B virus RNA by three ribozymes transcribed from a single DNA template. Biochem. Biophys. Res. Commun. 189:743-748.

24. Ruiz, J., Y. Ito, C.H. Wu, and G.Y. Wu. 1996. Multimeric tandem ribozymes against hepatitis B. Biotechniques. In press.

25. Wang, C., P. Sarnow, and A. Siddiqui. 1994. A conserved helical element is essential for internal initiation of translation of hepatitis $\mathrm{C}$ virus RNA. J. Virol. 68:7301-7307.

26. Fukushi, S., K. Katayama, C. Kurihara, N. Ishiyama, F.B. Hoshino, T. Ando, and A. Oya. 1994. Complete 5' noncoding region is necessary for the efficient internal initiation of hepatitis C virus RNA. Biochem. Biophys. Res. Commun. 199:425-432.

27. Rijnbrand, R., P. Bredenbeek, T. van der Straaten, L. Whetter, G. Inchauspe, S. Lemon, and W. Spaan. 1995. Almost the entire 5' non-translated region of hepatitis $\mathrm{C}$ virus is required for cap-independent translation. FEBS Lett. 365:115-119.

28. Yoo, B.J., M.J. Selby, J. Choe, B.S. Suh, S.H. Choi, J.S. Joh, G.J. Nuovo, H.S. Lee, M. Houghton, and J.H. Han. 1995. Transfection of a differentiated human hepatoma cell line (Huh7) with in vitro-transcribed hepatitis $\mathrm{C}$ virus (HCV) RNA and establishment of a long-term culture persistently infected with HCV. J. Virol. 69:32-38.

29. Enomoto, N., M. Kurosaki, Y. Tanaka, F. Marumo, and C. Sato. 1994 Fluctuation of hepatitis $\mathrm{C}$ virus quasispecies in persistent infection and interferon treatment revealed by single-strand conformation polymorphism analysis. J. Gen. Virol. 75:1361-1369.

30. Bertolini, L., S. Iacovacci, A. Ponzetto, G. Gorini, M. Battaglia, and G. Carloni. 1993. The human bone-marrow-derived B-cell line CE, susceptible to hepatitis C virus infection. Res. Virol. 144:281-285.

31. Carloni, G., S. Iacovacci, M. Sargiacomo, G. Ravagnan, A. Ponzetto, C Peschle, and M. Battaglia. 1993. Susceptibility of human liver cell cultures to hepatitis C virus infection. Arch. Virol. Suppl. 8:31-39.

32. Lanford, R.E. C. Sureau, J.R. Jacob, R. White, and T.R. Fuerst. 1994 Demonstration of in vitro infection of chimpanzee hepatocytes with hepatitis $\mathrm{C}$ virus using strand-specific RT/PCR. Virology. 202:606-614.

33. Shimizu, Y.K., A. Iwamoto, M. Hijikata, R.H. Purcell, and H. Yoshikura. 1992. Evidence for in vitro replication of hepatitis $\mathrm{C}$ virus genome in a human T-cell line. Proc. Natl. Acad. Sci. USA. 89:5477-5481. 